\title{
Charge Selective Function in Childhood Glomerular Diseases
}

\author{
SHORI TAKAHASHI, SAORI WATANABE, NAOHIRO WADA, HITOHIKO MURAKAMI, SATOSHI FUNAKI, KUNIMASA YAN, \\ YOSHIAKI KONDO, KENSUKE HARADA, AND MICHIO NAGATA
}

\begin{abstract}
Department of Pediatrics [S.T., S.W., H.M., S.F., K.H.], Nihon University School of Medicine, Tokyo, Japan 101-8309; Division of Nephrology [N.W.], Shizuoka Children's Hospital, Shizuoka, Japan, 420-0953; Department of Pediatrics [K.Y.], Kyorin University School of Medicine Tokyo, Japan 191-8611; Department of Pediatrics [Y.K.], Tohoku University School of Medicine Sendai, Japan 980-8575; Department of Pathology [M.N.] Institute of Basic Medical Sciences University of Tsukuba, Tsukuba, Japan 305-8575
\end{abstract}

\begin{abstract}
The charge selectivity (CS) function in human renal disease has not been unequivocally demonstrated to date. However, the clearance ratio of $\operatorname{IgA}$ to $\operatorname{IgG}$ may be theoretically useful in estimating CS in humans, since IgA and IgG have similar sizes and tertiary structures, but distinct isoelectric points $(3.5-5.5[\operatorname{IgA}]$ and 4.5-9.0 [IgG]), and Stokes-Einstein radius: $61 \AA(\operatorname{IgA})$ and $49-60 \AA$ (IgG). Two-dimensional electrophoresis with the following immunoblotting revealed that the considerably anionic portion (isoelectric points $[\mathrm{pI}]<4.0$ ) of IgA, visible in serum, was absent in the urine in steroid-sensitive nephrotic syndrome (SSNS) but present in the same during IgA nephropathy (IgAN) and membranoproliferative glomerulonephritis (MPGN). A latex assay revealed the CS index (CSI) was significantly low in patients with podocyte disease (group A), including SSNS, focal and segmental glomerulosclerosis (FSGS) and Finnish-type congenital nephrotic syndrome (FCNS), but high in those with Alport syndrome (AS), IgAN, Henoch-Schönlein purpura nephritis (HSPN), and MPGN (group B). The linear regression analysis of the $\operatorname{IgA}$ size selectivity index (IgA SSI; clearance ratio of $\operatorname{IgA}$ to transferrin) and SSI (clearance ratio of IgG to transferrin), which represents the clearance ratio of $\operatorname{IgA}$ to $\operatorname{IgG}$ referring to the transferrin clearance, revealed the influence of the charge more accurately. Indeed, the slope of the regression lines of IgA SSI $(y)$ to SSI $(x)$ were concluded to be $y=0.39 x$ (group A) and $y=1.05 x$ (group B), respectively. These results suggested that the charge selective barrier among podocyte diseases (group A) is preserved to some degree, but lost in cases of nephritis and AS (group B). (Pediatr Res 59: 336-340, 2006)
\end{abstract}

$\mathrm{T}_{1}$ he glomerular capillary wall (GCW) has been considered to have size- and charge-selective sieving functions for plasma proteins (1-3). There have been many approaches suggested to analyze the charge selective property of the GCW in relation to the proteinuria mechanism in various glomerular diseases in humans and animal models $(4,5)$. Representative research in the 1970s included differential clearance studies using charged and neutral dextran polymer $(6,7)$. However, the addition of sulfate moieties to the neutral dextran polymer resulted in the flexible dextran polymer being converted to a relatively more rigid dextran sulfate (DS) molecule $(1,8)$. In addition, DS tends to bind to plasma

Received June 13, 2005; accepted September 29, 2005

Correspondence: Shori Takahashi, M.D., Department of Pediatrics, Nihon University School of Medicine, 1-8-13 Chiyoda-ku, Kandasurugadai, Tokyo, Japan 101-8309; e-mail: shori@med.nihon-u.ac.jp

This work was supported by a Grant-in-Aid from the Japanese Society for Promotion of Science (17591118 to S. Takahashi).

DOI: 10.1203/01.pdr.0000196733.47083.81 proteins (5), meaning the calculated differential clearances of such molecules are influenced by the tertiary structure, protein binding and other factors as well as anionic charge, which resulted in the sieving coefficient being underestimated. Another trend analyzing the GCW charge selective property was the use of differential serum protein clearance with different charges $(9,10)$. However, there is a reabsorption problem associated with filtered proteins in renal proximal tubules that may influence their differential clearance ratio $(11,12)$. Moreover, the ionic strength of serum electrolytes should be taken into account $(13,14)$, especially considering the recent proposal that the glomerular basement membrane (GBM) is a type of ion exchange gel fiber $(15,16)$. It is likely that the plasma ionic strength, such as that of sodium at $0.14 \mathrm{~mol}$, may influence the electrical charge of most proteins to some degree, as is seen in ion exchange chromatography $(15,16)$. Therefore, these differential clearance studies, using proteins with minor differences in isoelectric points (pI), may not reflect the charge selective properties of the GCW.

Recent findings of the GCW molecular architecture and function revealed that GCW consists of three layers: the fenestrated endothelium with polyanionic charge, GBM, and the slit diaphragm of the interdigitating podocyte foot processes. These barriers are assumed to play different roles for protein-sieving properties, although mutual interaction between the functions of each layer is likely $(3,17)$, making it difficult to distinguish each role clearly. Moreover, an antithesis for the existence of the charge selective barrier in GCW has recently been proposed $(11,18,19)$. With this in mind, the above settings mean the charge-selective protein-sieving function of GBM, previously long estimated, must be reconsidered.

Previously, we showed the presence of a preferential protein reabsorption mechanism with cationic charge in renal proximal tubules by analyzing the charge diversity of the serum and urinary IgG molecule (20). In this study, we noted that IgA and IgG have similar molecular sizes and distinct molecular pI. IgA molecules have a Stokes-Einstein radius of
Abbreviations: AS, Alport syndrome; CSI, charge selectivity index; FCNS, Finnish-type congenital nephrotic syndrome; FSGS, focal and segmental glomerulosclerosis; GBM, glomerular basement membrane; GCW, glomerular capillary wall; IgAN, IgA nephropathy; IgA SSI, IgA size selectivity index; MPGN, membranoproliferative glomerulonephritis; SSNS, steroidsensitive 
$61 \AA$ and pI of 3.5-5.5, while IgG molecules have a StokesEinstein radius of 49-60 $\AA$ and $\mathrm{pI}$ of 4.5-9. In addition, x-ray analysis showed similarities in the tertiary structures between $\operatorname{IgG}$ and $\operatorname{IgA}(21)$, hence both were regarded as appropriate molecules for use in analyzing the GCW charge selective function by differential clearance. We defined $\operatorname{IgA} / \mathrm{IgG}$ clearance in terms of a CSI for at least the size of these molecules. If the CSI is low, the charge-selective sieving property may function, although it may not function if the former approaches 1.0. The SSI was also calculated using the differential clearance of $\operatorname{IgG}$ and transferrin $(22,23)$.

The present study aimed to find the way in which glomerular charge-selective properties altered in childhood nephrosis using CSI. Interestingly, the charge-selective function was found to be preserved in nephrosis, including SSNS, FSGS, and FNS but had deteriorated in the case of proliferative glomerular disease and AS. Our results suggest a different mechanism of proteinuria active in nephrosis and nephritis.

\section{MATERIALS AND METHODS}

Patients. A total of 113 pediatric patients, aged 1-17, who had been admitted to Surugadai Nihon University and Shizuoka Children's Hospitals were analyzed. We studied plasma and urine samples, obtained on the same day from patients with various renal diseases as follows: AS ( $n=8$, biopsy proven), HSPN ( $n=20$, biopsy proven), $\operatorname{IgAN}(n=39$, biopsy proven), MPGN ( $n=5$, biopsy proven), FSGS $(n=4$, biopsy proven), FNS $(n=1$, clinicopathologically and genetically proven), and SSNS $(n=36)$. None of these patients were at a stage of chronic renal failure (glomerular filtration rate $<60 \mathrm{~mL} / \mathrm{min}$ ). The degree of proteinuria of each disease is listed in Table 1.

Determination of Serum and Urinary Concentration of IgA, IgG, and Transferrin. Both serum and urinary IgA and IgG were measured by latex assay using LA-2000 (Analytical Instruments Co. Ltd.). The latex beads were coated with rabbit antisera against human $\operatorname{IgG}$ ( $\gamma$ chain; Eiken, Japan) and $\operatorname{IgA}$ ( $\alpha$ chain, Eiken). Serum and urinary transferrin were measured by laser nephelometry (Boehringer nephelometer analyzer; Boehringer, Germany) with antibodies against human transferrin (Boehringer, Germany).

Definitions of CSI, SSI, and IgA SSI. CSI is defined as the ratio of the IgA clearance to that of IgG, while the SSI is defined as the ratio of IgG clearance to that of transferrin. As the latter has virtually identical pI distribution to IgA, we calculated the ratio of the $\operatorname{IgA}$ clearance to that of transferrin in terms of the IgA SSI.

Electrophoresis. Two-dimensional (2D) electrophoresis was performed according to the Goerg method (25) using the Phast system (Pharmacia, Uppsala, Sweden). Precast Phast Gel IEF 3-9 was used for isoelectric focusing (IEF), and Phast Gel gradient 10-15 was used for sodium-dodecyl sulfate PAGE (SDS-PAGE). SDS-PAGE was performed under nonreducing conditions. Urinary proteins separated by IEF were equilibrated on the gel in a buffer composed of $0.112 \mathrm{~mol} / \mathrm{L}$ acetic acid, $0.112 \mathrm{~mol} / \mathrm{L}$ Toris, and $2 \%$ SDS. The gels were then subjected to SDS-PAGE. This technique involved proteins being separated according to the molecular $\mathrm{pI}$ along the horizontal axis and molecular weight along the vertical axis.

Immunoblotting. After 2D electrophoresis, the separated proteins were electrophoretically transferred to a nitrocellulose membrane, which was then treated with rabbit antisera against human IgA ( $\alpha$ chain; DAKO, Copenhagen,

Table 1. Profiles of the patients

\begin{tabular}{|c|c|c|}
\hline & $n$ & $\begin{array}{l}\text { U Pro/Cre mean } \\
( \pm \text { SEM })\end{array}$ \\
\hline Alport & 8 & $1.19(0.39)$ \\
\hline HSPN & 20 & $7.29(3.81)$ \\
\hline IgAN & 39 & $1.02(0.13)$ \\
\hline MPGN & 5 & $0.81(\mathrm{ND})] * *$ \\
\hline FSGS & 4 & 27.1 (ND) \\
\hline FCNS & 1 & 15.5 (ND) \\
\hline SSNS & 36 & $18.24(3.12)$ \\
\hline
\end{tabular}

* $F$ test, $p<0.000001$.

$\mathrm{ND}$, not done.
Denmark), IgG ( $\gamma$ chain; DAKO), and transferrin (DAKO). After washing, the membrane was treated with horseradish peroxidase-conjugated antiserum against rabbit IgG (no cross to human IgG; Cappel, PA), and the peroxidase reaction was then performed.

Statistical Analysis. Results were expressed as mean \pm SEM and as mean $\pm \mathrm{SD}$, while the mean variables were compared by an unpaired $t$ test, and correlations were studied by linear regression analysis using InStat3.

\section{RESULTS}

Immunoblotting Analysis of IgA, IgG, and Transferrin. Two-dimensional immunoblotting of serum and urinary $\operatorname{IgG}$ and IgA of a patient with SSNS, at the time of relapse, is shown in Figure 1A. Despite relatively similar molecular weights of $\operatorname{Ig} \mathrm{A}$ and $\operatorname{IgG}$ in the serum and urine samples, there were distinct differences in the $\mathrm{pI}$ of $\operatorname{IgA}$ and $\mathrm{IgG}$. In the serum samples, the $\mathrm{pI}$ of $\operatorname{IgA}$ and $\mathrm{IgG}$ ranged from 3.5 to 5.2 and 5.5 to 9 , respectively. However, the $\mathrm{pI}$ of $\operatorname{IgA}$ and $\operatorname{IgG}$ from the urine samples ranged from 5.0 to 5.2 and 6.0 to 8.5 , respectively. In other words, the predominantly cationic portion ( $\mathrm{pI}>8.5$ ) of $\operatorname{IgG}$ and predominantly anionic portion $(\mathrm{pI}<5.0)$ of IgA were absent in the SSNS urine samples. In contrast, the urinary IgA showed almost the same charge diversity as that of the serum samples in

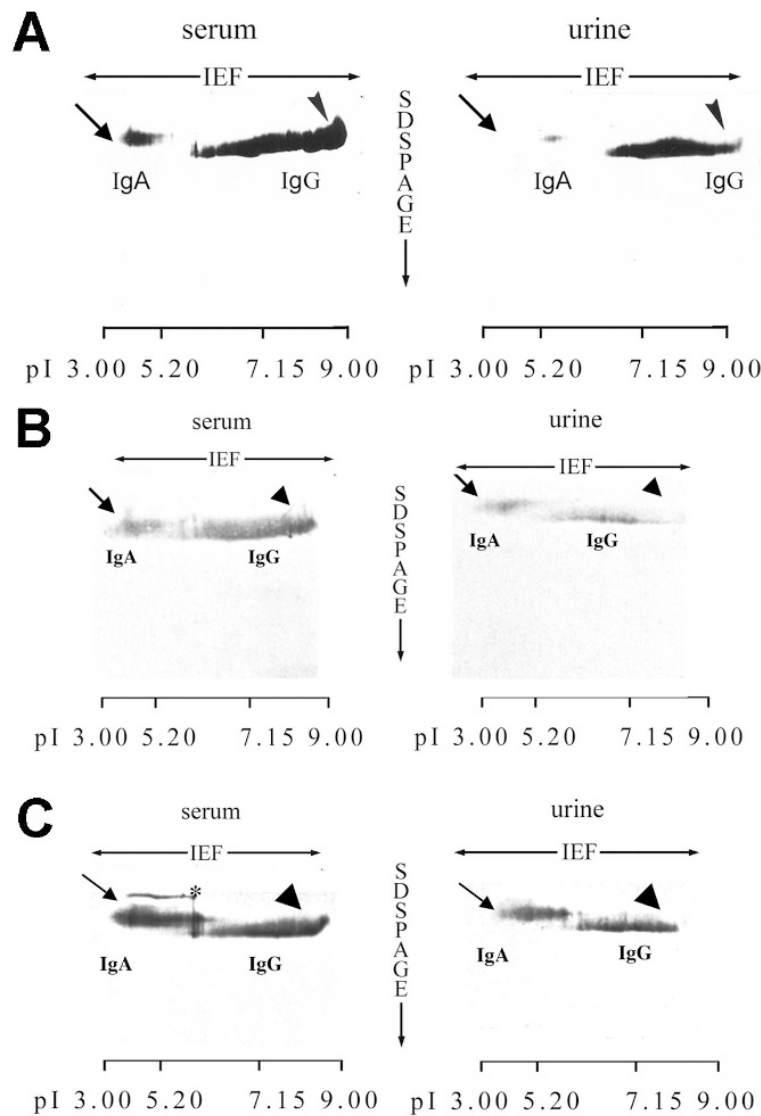

Figure 1. Two-dimensional immunoblotting of serum and urinary $\operatorname{IgG}$ and $\operatorname{IgA}$ of a patient with SSNS. The considerably cationic portion of $\operatorname{IgG}(\mathrm{pI}>8$, arrowhead) and the considerably anionic portion of $\operatorname{IgA}(\mathrm{pI}<4.0$, arrow) are missing in the urine sample when compared with the serum sample $(A)$. However, the considerably anionic portion of $\operatorname{IgA}(\mathrm{pI}<4.0$, arrow) is present in the urine of a patient with $\operatorname{IgAN}$, while the considerably cationic portion of $\operatorname{IgG}$ ( $\mathrm{pI}>8$, arrowhead) of the urine is missing $(B)$. The considerably anionic portion of $\operatorname{IgA}(\mathrm{pI}<4.0$, arrow) is also present in the urine of a patient with MPGN, while the considerably cationic portion of $\operatorname{IgG}(\mathrm{pI}>8$, arrowhead $)$ of the urine is missing in this case $(C)$. These urinary protein blots are representative, and the pattern is similar in other cases of the same disease. 
IgAN (Fig. 1B) and in MPGN (Fig. 1C). However, the considerably cationic portion of IgG, while present in the serum sample, was found to be markedly decreased in the urine samples. The lower molecular weight fragments of $\operatorname{IgA}$ and $\mathrm{IgG}$ were undetected, while the higher molecular weight band of $\operatorname{IgA}$ was only visible in the serum of a MPGN patient (Fig. 1C).

The charge and molecular weight distribution of $\operatorname{IgA}, \operatorname{IgG}$, and transferrin in both the urine and serum samples from an SSNS patient were analyzed using 2D immunoblotting (Fig. 2). IgA and transferrin showed similar pI. In addition, the considerably cationic portion of $\operatorname{IgG}$ was decreased while the anionic equivalent of IgA was absent in the urine sample as observed in another SSNS patient (Fig. 1A).

CSI (Clearance Ratio of IgA to IgG), SSI (Clearance Ratio of IgG to Transferrin), and IgA SSI (Clearance Ratio of IgA to Transferrin)

The values of CSI, SSI, and IgA SSI in various glomerular diseases are listed in Table 2. The mean ( \pm SEM) CSI values were as follows: AS $(1.18 \pm 0.32)$, HSPN $(1.1 \pm 0.33)$, IgAN (1.18 \pm 0.35$)$, MPGN (1.33), FSGS (0.42), FCNS (0.37), and SSNS $(0.56 \pm 0.14)$. Although there were no significant differences between the CSI values of AS, HSPN, IgAN and MPGN, significant difference was apparent between these diseases (group A) and podocyte diseases (FSGS, FCNS, and SSNS; group B). We further evaluated the difference of CSI between groups A and B. The mean $( \pm$ SD) value of groups A and B was $0.57( \pm 0.13)$ and $1.17( \pm 0.35)$, respectively, with significant difference apparent $(p<0.0001$, indicated by the asterisk in Table 2$)$.

The relationship between CSI and the degree of proteinuria (urinary protein/creatinine ratio [U Prot/Cre]) is shown in Figure 3. Regression analysis revealed no correlation between CSI and U Prot/Cre in these patients.

The relationship between SSI and CSI is shown in Figure 4. Although no correlation was found between the two, as SSI approaches 1.0, the CSI of group A tends to approach 0.4 and that of group $\mathrm{B}$ tends to approach 1.0. Consequently, the distribution of groups A and B is clearly different.

SSI positively correlates with IgA SSI. However, as previously mentioned, the distribution of group A is clearly different from that of group B. The correlations, analyzed separately
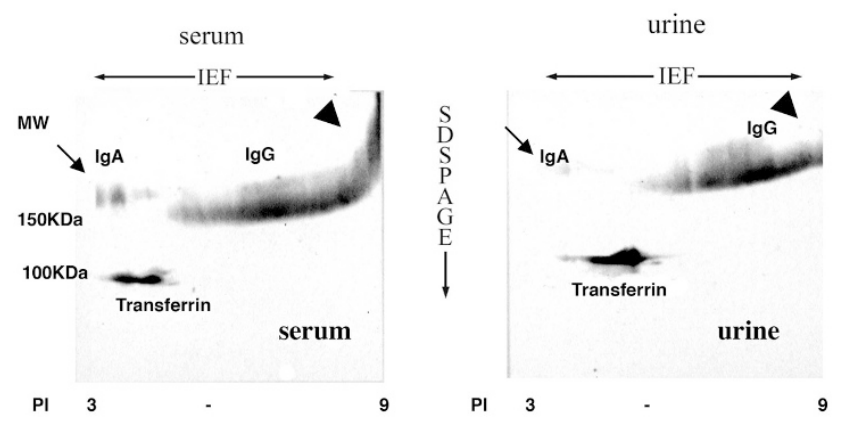

Figure 2. Two-dimensional immunoblotting of serum and urinary $\operatorname{IgG}, \operatorname{IgA}$, and transferrin of a patient with SSNS. The charge diversity (pI) of the IgA and transferrin is almost identical, while the $\mathrm{pI}$ of $\mathrm{IgG}$ and transferrin remain distinct. The considerably cationic portion of $\operatorname{IgG}(\mathrm{pI}>8$, arrowhead $)$ and the considerably anionic portion of $\operatorname{IgA}(\mathrm{pI}<4.0$, arrow) are missing in the urine sample when compared with the serum sample. The immunoblotting pattern of $\operatorname{IgG}$ and $\operatorname{IgA}$ are almost identical to that in another SSNS patient (Fig. 1A).
Table 2. Values of CSI, SSI, and IgA in various glomerular diseases

\begin{tabular}{|c|c|c|c|c|c|}
\hline & $n$ & $\begin{array}{l}\text { CSI mean } \\
( \pm \text { SEM })\end{array}$ & & $\begin{array}{l}\text { SSI mean } \\
( \pm \text { SEM })\end{array}$ & $\begin{array}{l}\text { IgA SSI mean } \\
\quad( \pm \text { SEM })\end{array}$ \\
\hline Alport & 8 & $1.18(0.32)$ & & $0.28(0.04)$ & $0.29(0.04)$ \\
\hline HSPN & 20 & $1.1(0.33)$ & & $0.24(0.02)$ & $0.24(0.01)$ \\
\hline $\operatorname{IgAN}$ & 39 & $1.18(0.35)$ & & $0.27(0.02)$ & $0.27(0.02)$ \\
\hline MPGN & 5 & $1.33(\mathrm{ND})$ & * & $0.36(\mathrm{ND})$ & 0.45 (ND) \\
\hline FSGS & 4 & 0.42 (ND) & & 0.44 (ND) & 0.16 (ND) \\
\hline FCNS & 1 & $0.37(\mathrm{ND})$ & & 0.37 (ND) & 0.12 (ND) \\
\hline SSNS & 30 & $0.56(0.14)$ & & $0.074(0.01)$ & $0.04(0.003)$ \\
\hline
\end{tabular}

$* F$ test, $p<0.000001$.

$\mathrm{ND}$, not done.

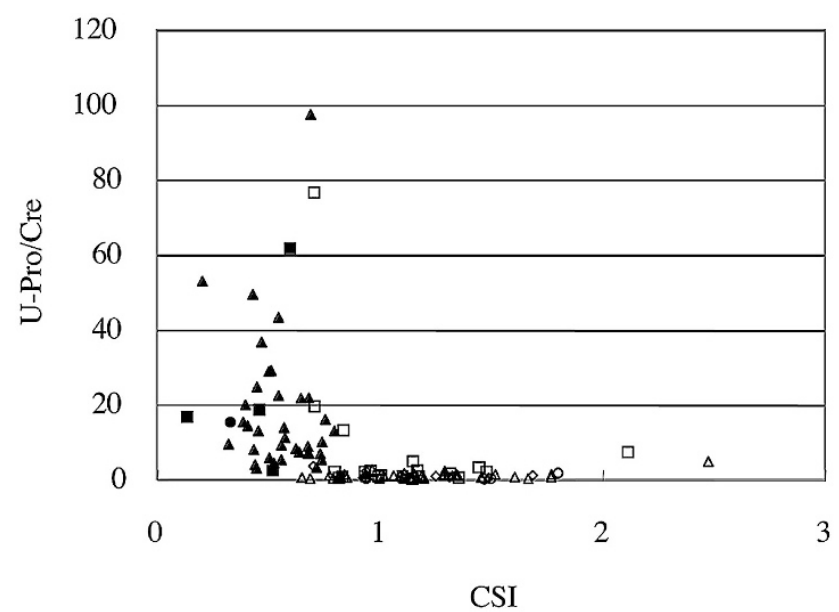

Figure 3. There was no correlation between the degree of proteinuria (U Pro/Cre) and the CSI. Symbols are indicated as follows: AS ( ), HSPN ( $\square$ ), $\operatorname{IgAN}(\triangle)$, MPGN $(\bigcirc)$, FSGS $(\square)$, FCNS $(\bullet)$, SSNS $(\boldsymbol{\bullet})$.

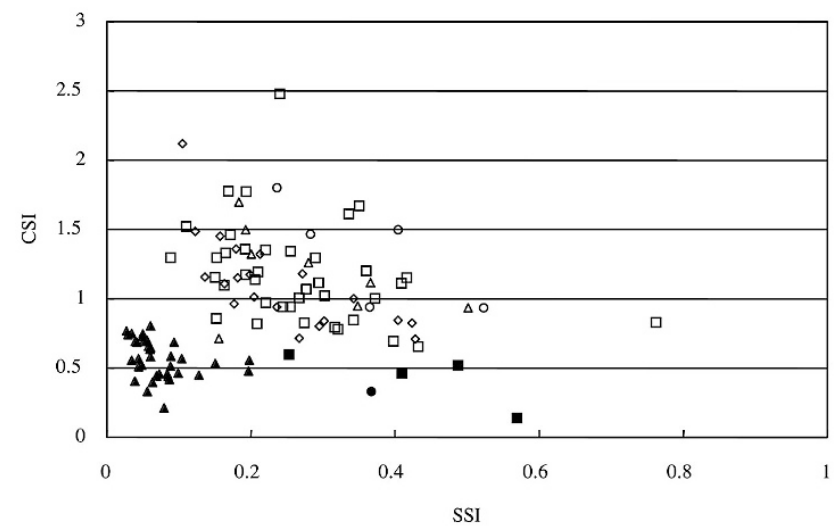

Figure 4. There is no correlation between the values of SI and CSI. However, as SSI approaches 1.0, the CSI of group A (open symbols) tends to approach 1.0 and that of group B (filled symbols) tends to approach 0.5. The distribution of group B is clearly different from that of group A. Symbols are indicated as follows: AS $(\diamond), \operatorname{HSPN}(\square), \operatorname{IgAN}(\triangle), \operatorname{MPGN}(\bigcirc), \operatorname{FSGS}(\square)$, FCNS $(\bullet)$, SSNS $(\boldsymbol{\Delta})$.

with these groups, are shown in Figure 5. The slope of the regression line of group A is $1.05(p<0.0001 ; 95 \%$ confidence interval $[\mathrm{CI}], 0.98-1.12$ ), while in contrast, that of group B is 0.39 ( $p<0.0001 ; 95 \% \mathrm{CI}, 0.33-0.44)$.

\section{DISCUSSION}

$\operatorname{IgA}$ and $\operatorname{IgG}$ are similar in terms of tertiary structure and molecular size. Two-dimensional immunoblotting of $\operatorname{IgG}$ and 


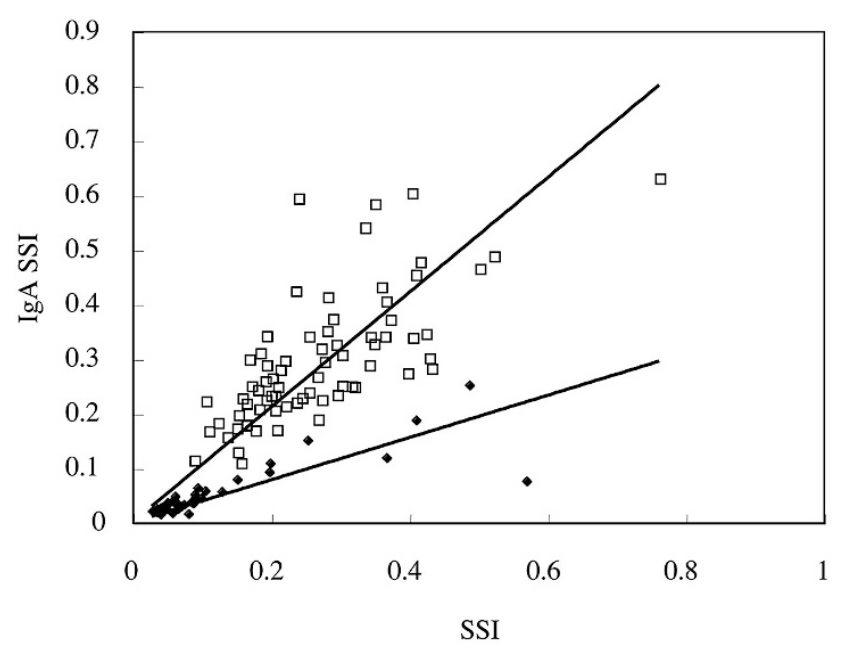

Figure 5. SSI and IgA SSI of group A (open symbols) correlate with a slope of 1.05 ( $p<0.0001 ; 95 \% \mathrm{CI}, 0.98-1.12)$, reflecting the values of the CSI of group A. SSI and IgA SI correlate with a slope of $0.39(p<0.0001,95 \%$ CI, $0.33-0.44)$ reflecting the values of the CSI of group B (filled symbols).

$\operatorname{IgA}$ indicates that most IgA possesses a stronger negative charge than $\operatorname{IgG}$ as shown in Figures $1 A-C$ and 2. Moreover, the considerably anionic portion of $\operatorname{Ig} \mathrm{A}$, previously detected in the serum samples, was found to be absent in urine samples from SSNS patients (Figs. $1 A$ and 2). Conversely, however, it was present in urine samples from IgAN and MPGN (Fig. 1B, $C)$. These characteristics render IgA and IgG suitable candidates for analyzing the charge dependent differential clearance of the GCW. We therefore used these well-characterized proteins to study the CS of the protein-sieving function in patients with various glomerular diseases. Although the considerably cationic portion of $\mathrm{IgG}$ of those detected in the serum samples was found to be absent or decreased in all the urine samples, this portion of $\operatorname{IgG}$ could be reabsorbed in the renal proximal tubules. In addition, the influence of IgA and $\mathrm{IgG}$ in polymeric or fragmented form must be considered. Two-dimensional immunoblotting of the serum and urine samples did not detect any polymeric or fragmented IgA, except a higher molecular weight band of serum $\operatorname{IgA}$ of an MPGN patient, rendering this band a potential IgA dimer. Since the CSI differed significantly between groups A and B, these findings suggest that the influence of IgA polymer has a negligible effect on the CSI calculation.

The mean CSI value in patients with HSPN, IgAN, MPGN, and AS (group B) was 1.17. This result suggests that the fractional clearance of $\operatorname{IgA}$ is greater than that of $\operatorname{IgG}$ in those patients. However, from a physiologic perspective, it is unlikely that the larger proteins carrying greater negative charges would preferentially permeate the capillary wall. Therefore, we considered the tubular reabsorption of cationic $\operatorname{IgG}$ as causing a decrease in IgG fractional clearance and resulting in an apparent increase in the CSI value $>1.0$. We previously showed the cationic charge preferential tubular reabsorption mechanism of IgG (20), which may influence CSI. Taking this phenomenon into account for the above results, it is possible to consider CSI values exceeding 1.0 to be 1.0 in reality, meaning the charge selective protein-sieving function may not work on the proteinuria of these diseases. The decrement of anionic sites in the GBM of these diseases $(26,27)$ as well as the ultrastructural GBM changes $(28,29)$ may support the loss of the charge selective barrier.

The mean CSI value in patients with FSGS, FCNS, and SSNS (group A) was 0.57 . These results suggest that the fractional clearance of $\operatorname{IgA}$ was much less than that of IgG. Considering the minor differences in the molecular Stokes-Einstein radius between IgA and IgG, this large difference in the fractional clearance may result from the strong negative charge of the $\operatorname{IgA}$ molecules. In other words, the charge selective barrier of the capillary wall may function in these diseases to some degree.

CSI did not correlate with the degree of proteinuria (protein/creatinine ratio). However, no heavy proteinuria is observed when CSI values exceed 1.0, although conversely it is observed with CSI values $<0.7$. These results suggest that the degree of proteinuria is not merely dependent on the impairment of the CS of the glomerular capillary wall. The diseases in group B include morphologic GBM changes, and dense deposition or mesangial proliferation to varying extents. The degree to which such changes in renal pathology are distributed may rather reflect the degree of proteinuria (30).

It has been suggested that the ratio of IgG clearance to transferrin clearance represents the size selectivity of the glomerular diseases (SSI) (23) and this conventional index has been widely used $(31,32)$. Therefore, it is essential to investigate the CSI-SSI relationship to assess the independence of each index. The results revealed no obvious correlation between the two, suggesting that CSI is hardly influenced by the size selectivity of the GCW. CSI and SSI are unrelated parameters demonstrating that CS and size selectivity have independent biologic determinants. However, as SSI approaches 1.0, the CSI of group B also tends to approach 1.0 while that of group A tends to approach 0.4. The clear difference in the distribution of groups A and B indicated that CSI and SSI are independent and that although the charge selective barrier may not function on group $\mathrm{B}$, it may function to some extent on group A of the podocyte diseases.

The relationship between IgA SSI and SSI gives more accurate information about the charge. The scatter diagram of IgA SSI and SSI revealed a distinct distribution for groups A and $\mathrm{B}$. The difference in these distributions seems to result from differences in CS because this relationship is based on the clearance ratio of $\operatorname{IgA}$ to $\operatorname{IgG}$, referring to the transferrin clearance. Indeed, the slope of the group B regression line resulted in 1.05, suggesting that IgA was equally filtered as $\mathrm{IgG}$ to the degree in all SSI. In contrast, the group A regression line resulted in 0.39 , suggesting that the charge selective property is preserved in these nephrosis (podocyte diseases) and filtered $39 \%$ of IgA when compared with IgG. These positive linear correlations and the distinct slopes in both groups indicate the influence of the charge selective barrier.

The GBM poses anionic sites (33) consisted of glucosaminoglycans (34) and the decrement of such sites is presumed to reflect dysfunction of the charge selective barrier in nephrotic syndrome $(26,34,35)$. In addition, the differential clearance study by Lund et al. (36) using neutral and native forms of albumin indicated that the fractional clearance of neutral albumin 
is 10 times greater than that of the native (anionic) albumin in vivo. Therefore, although remaining functional, the CS can be presumed to be weakening in group A, podocyte diseases.

As we were unable to examine CSI, SSI, and IgA SSI with a normal glomerular filtrate, which is difficult to obtain from human subjects, we do not have normal values for these indices. However, the difference in CSI between groups A and $\mathrm{B}$ indicates differences in the proteinuria origin that have yet to be postulated. The most important difference in pathology between groups A and B might be the degree of foot process effacement. Recently, several studies indicated impaired nephrin and podocin $(37,38)$ expression in some cases of SSNS and steroid-resistant nephrotic syndrome as well as in FCNS (2) and familial SSNS (39). Thus, the essential difference between groups A and B might be based on the degree to which the slit diaphragm is dysfunctional. The slit diaphragm is intended as a central size-selective filtration barrier (40). Recent studies by Jeansson and Haraldsson (41) suggested the importance of endothelial glycocalyx in the charge-selective property of GCW. Unless impairment of the slit diaphragm may influence the anionic sites of GBM (35), the group A diseases are not likely to completely lose their charge-selective properties. This is supported by the cases of FCNS and FSGS since these diseases showed a worse SI with a better CSI than group A.

The most interesting fact in this study is that CS was evenly preserved in all of SSNS, FCNS, and FSGS, but the size selectivity was deteriorated in FCNS and FSGS. Although GBM changes among these diseases did not apparently differ, more precise GBM architecture as well as the difference in intraglomerular blood flow should be investigated to elucidate the mechanism regulating the size-selective barrier.

In conclusion, the present study suggests that the charge selective barrier functions to some degree in SSNS, FSGS, and FCNS, the podocyte diseases, while in contrast, it is completely impaired in the cases of AS, HSPN, IgAN, and MPGN. The conventional CSI proposed by the present study provides a new insight into the charge-selective mechanism in proteinuria in human glomerular diseases.

\section{REFERENCES}

1. Kanwar YS 1984 Biophysiology of glomerular filtration and proteinuria. Lab Invest 51:7-21

2. Tryggvason K 1999 Unraveling the mechanisms of glomerular ultrafiltration: nephrin, a key component of the slit diaphragm. J Am Soc Nephrol 10:2440-2445

3. Deen WM, Lazzara MJ, Myers BD 2001 Structural determinants of glomerular permeability. Am J Physiol Renal Physiol 281:F579-596

4. Brenner BM, Hostetter TH, Humes HD 1978 Molecular basis of proteinuria of glomerular origin. N Engl J Med 298:826-833

5. Guasch A, Deen WM, Myers BD 1993 Charge selectivity of the glomerular filtration barrier in healthy and nephrotic humans. J Clin Invest 92:2274-2282

6. Chang RL, Deen WM, Robertson CR, Brenner BM 1975 Permselectivity of the glomerular capillary wall: III. Restricted transport of polyanions. Kidney Int 8:212-218

7. Bohrer MP, Baylis C, Humes HD, Glassock RJ, Robertson CR, Brenner BM 1978 Permselectivity of the glomerular capillary wall. Facilitated filtration of circulating polycations. J Clin Invest 61:72-78

8. Rennke HG, Patel Y, Venkatachalam MA 1978 Glomerular filtration of proteins: clearance of anionic, neutral, and cationic horseradish peroxidase in the rat. Kidney Int 13:278-288

9. Olson JL, Rennke HG, Venkatachalam MA 1981 Alterations in the charge and size selectivity barrier of the glomerular filter in aminonucleoside nephrosis in rats. Lab Invest 44:271-279

10. Hemmelder MH, de Zeeuw D, de Jong PE 1997 Measurement of glomerular charge selectivity in non-diabetic renal disease. Nephrol Dial Transplant 12:57-62

11. Osicka TM, Comper WD 1998 Tubular inhibition destroys charge selectivity for anionic and neutral horseradish peroxidase. Biochim Biophys Acta 1381:170-178
12. Birn H, Vorum H, Verroust PJ, Moestrup SK, Christensen EI 2000 Receptorassociated protein is important for normal processing of megalin in kidney proximal tubules. J Am Soc Nephrol 11:191-202

13. Bolton GR, Deen WM, Daniels BS 1998 Assessment of the charge selectivity of glomerular basement membrane using Ficoll sulfate. Am J Physiol 274:F889-F896

14. Sorensson J, Ohlson M, Lindstrom K, Haraldsson B 1998 Glomerular charge selectivity for horseradish peroxidase and albumin at low and normal ionic strengths. Acta Physiol Scand 163:83-91

15. Ohlson M, Sorensson J, Haraldsson B 2001 A gel-membrane model of glomerular charge and size selectivity in series. Am J Physiol Renal Physiol 280:F396-F405

16. Smithies O 2003 Why the kidney glomerulus does not clog: a gel permeation/ diffusion hypothesis of renal function. Proc Natl Acad Sci U S A 100:4108-4113

17. Edwards A, Daniels BS, Deen WM 1999 Ultrastructural model for size selectivity in glomerular filtration. Am J Physiol 276:F892-F902

18. Greive KA, Nikolic-Paterson DJ, Guimaraes MA, Nikolovski J, Pratt LM, Mu W, Atkins RC, Comper WD 2001 Glomerular permselectivity factors are not responsible for the increase in fractional clearance of albumin in rat glomerulonephritis. Am J Pathol 159:1159-1170

19. Guimaraes MA, Nikolovski J, Pratt LM, Greive K, Comper WD 2003 Anomalous fractional clearance of negatively charged Ficoll relative to uncharged Ficoll. Am J Physiol Renal Physiol 285:F1118-F1124

20. Takahashi S, Wada N, Harada K, Nagata M 2004 Cationic charge-preferential IgG reabsorption in the renal proximal tubules. Kidney Int 66:1556-1560

21. Rudikoff S, Potter M, Segal DM, Padlan EA, Davies DR 1972 Crystals of phosphorylcholine-binding Fab-fragments from mouse myeloma proteins: preparation and X-ray analysis. Proc Natl Acad Sci U S A 69:3689-3692

22. Kakuhara T, Hanzawa S, Nakayama S, Kanaguchi T, Ohara K 1975 Reassessment of selectivity index in nephrotic syndrome with special reference to the clinical significance of a small-molecular IgG fraction in the urine. Contrib Nephrol 4:83-95

23. Ellis D, Buffone GJ 1981 Protein clearances and selectivity determinations in childhood nephrosis: a reappraisal. Clin Chem 27:1397-1400

24. Sako M, Nakanishi K, Obana M, Yata N, Hoshii S, Takahashi S, Wada N, Takahashi Y, Kaku Y, Satomura K, Ikeda M, Honda M, Iijima K, Yoshikawa N 2005 Analysis of NPHS1, NPHS2, ACTN4, and WT1 in Japanese patients with congenital nephrotic syndrome. Kidney Int 67:1248-1255

25. Gorg A, Postel W, Gunther S, Friedrich C 1988 Horizontal two-dimensional electrophoresis with immobilized $\mathrm{pH}$ gradients using PhastSystem. Electrophoresis 9:57-59

26. Wada N, Ueda Y, Iidaka K, Inage Z, Kikkawa Y, Kitagawa T 1990 Portions of basement membrane with decreased negative charge in various glomerulonephritis. Clin Nephrol 34:9-16

27. Sakagami Y, Nakajima M, Takagawa K, Ueda T, Akazawa H, Maruhashi Y, Shimoyama H, Kamitsuji H, Yoshioka A 2004 Analysis of glomerular anionic charge status in children with IgA nephropathy using confocal laser scanning microscopy. Nephron Clin Pract 96:c96-c104

28. Lee HS, Choi Y, Lee JS, Yu BH, Koh HI 1989 Ultrastructural changes in IgA nephropathy in relation to histologic and clinical data. Kidney Int 35:880-886

29. Nomura Y, Ohya N, Shimada M 1989 A histopathological study on the prognosis of childhood IgA nephropathy and glomerular basement membrane lesions. Pediatr Nephrol 3:242-247

30. Hattori S, Karashima S, Furuse A, Terashima T, Hiramatsu M, Murakami M, Matsuda I 1985 Clinicopathological correlation of IgA nephropathy in children. Am J Nephrol 5:182-189

31. Hiraoka M, Takeda N, Tsukahara H, Kimura K, Takagi K, Hayashi S, Kato E, Ohta K, Sudo M 1995 Favorable course of steroid-responsive nephrotic children with mild initial attack. Kidney Int 47:1392-1393

32. Ramjee G, Coovadia HM, Adhikari M 1997 Comparison of noninvasive methods for distinguishing steroid-sensitive nephrotic syndrome from focal glomerulosclerosis. J Lab Clin Med 129:47-52

33. Caulfield JP, Farquhar MG 1976 Distribution of annionic sites in glomerular basement membranes: their possible role in filtration and attachment. Proc Natl Acad Sci U S A 73:1646-1650

34. Kanwar YS, Linker A, Farquhar MG 1980 Increased permeability of the glomerular basement membrane to ferritin after removal of glycosaminoglycans (heparan sulfate) by enzyme digestion. J Cell Biol 86:688-693

35. Fujigaki Y, Nagase M, Hidaka S, Matsui K, Shirai M, Nosaka H, Kawachi H, Shimizu F, Hishida A 1998 Altered anionic GBM components in monoclonal antibody against slit diaphragm-injected proteinuric rats. Kidney Int 54:1491-1500

36. Lund U, Rippe A, Venturoli D, Tenstad O, Grubb A, Rippe B 2003 Glomerularfiltration rate dependence of sieving of albumin and some neutral proteins in rat kidneys. Am J Physiol Renal Physiol 284:F1226-F1234

37. Lahdenkari AT, Kestila M, Holmberg C, Koskimies O, Jalanko H 2004 Nephrin gene (NPHS1) in patients with minimal change nephrotic syndrome (MCNS). Kidney Int 65:1856-1863

38. Caridi G, Bertelli R, Di Duca M, Dagnino M, Emma F, Onetti Muda A, Scolari F, Miglietti N, Mazzucco G, Murer L, Carrea A, Massella L, Rizzoni G, Perfumo F, Ghiggeri GM 2003 Broadening the spectrum of diseases related to podocin mutations. J Am Soc Nephrol 14:1278-1286

39. Boute N, Gribouval O, Roselli S, Benessy F, Lee H, Fuchshuber A, Dahan K, Gubler MC, Niaudet P, Antignac C 2000 NPHS2, encoding the glomerular protein podocin, is mutated in autosomal recessive steroid-resistant nephrotic syndrome. Nat Genet 24:349-354

40. Tryggvason K, Wartiovaara J 2001 Molecular basis of glomerular permselectivity. Curr Opin Nephrol Hypertens 10:543-549

41. Jeansson M, Haraldsson B 2003 Glomerular size and charge selectivity in the mouse after exposure to glucosaminoglycan-degrading enzymes. J Am Soc Nephrol 14:1756-1765 